\title{
Diet and Nutritional Situation of the Population in the Severely Drought Affected Areas of Gujarat
}

\author{
R. Hari Kumar, K. Venkaiah, N. Arlappa, Sharad Kumar, G. N. V. Brahmam and \\ K. Vijayaraghavan \\ Division of Field Studies, National Institute of Nutrition (ICMR), Jamai - Osmania (PO), \\ Hyderabad 500 007, Andhra Pradesh, India
}

KEYWORDS Drought. Food Security. Anthropometry. Undernutrition. Chronic Energy Deficiency.

\begin{abstract}
A cross-sectional survey was undertaken in three severely affected districts of Gujarat, to assess the impact of drought on diet and nutritional status of the population, household $(\mathrm{HH})$ food security, the coping strategies adopted by the community and the extent of $\mathrm{HH}$ participation in relief works were also assessed. Food insecurity was reported by about half of the HHs and almost all the HHs reported scarcity of fodder and water, community opted for cheaper foods and reduced the food consumption. Participation of the community in relief programmes was minimal. The consumption of cereals and millets was adequate but the diets were deficient in energy, vitamin A, riboflavin, niacin and vitamin C. About half of the preschool children were underweight ( $<75 \%$ of standard weight for age). Stunting and wasting was about $49 \%$ and $30 \%$ respectively. About half of the adult males and a third of females suffered chronic energy deficiency (BMI < 18.5). Drop in rainfall, cultivated area, failure of crops and a marginal increase of cattle deaths were reported. It was observed that during the current drought, though the food intakes reduced marginally, the adverse affects on nutritional status was perhaps prevented by the efficient food for work programme and PDS. Strengthening of health care, PDS, creation of subsidiary employment on permanent basis, maintaining adequate food stocks, forecasting drought, Nutritional surveillance of the community will go a long way in controlling the adverse affects of natural calamities.
\end{abstract}

\section{INTRODUCTION}

India experienced drought during the year 2000 in four states viz. Andhra Pradesh, Gujarat, Orissa and Rajasthan covering a total of one hundred and eleven districts, due to scanty or deficient rainfall. Natural calamities like droughts, famine or floods are known to affect adversely the country's economy in terms of drop in agricul-tural production and agro based industrial output, rise in rural unemployment, decrease in purchasing power, reduced household $(\mathrm{HH})$ food security, migration of rural labour force to urban areas, large scale movement or deaths of cattle etc. Household food insecurity may arise from failure of income from livestock, failure in agricultural production, under employment etc. Food security at the household level is influenced by accessibility to food, in terms of food availability, food prices and purchasing power of the households.

The studies conducted by Swaminathan et

Address Correspondence to: Dr. R. Hari Kumar, Sr. Research Officer, Division of Field Studies, National Institute of Nutrition, Jamai - Osmania (PO), Hyderabad 500 007, Andhra Pradesh, India

Telphone: 040-27008921-255//294, Fax: 040-27019141,

E-mail: drharikumar1959@Yahoo.co.in al. (1966) in the State of Andhra Pradesh had revealed a considerable reduction in cereal intakes, with a fifth of HHs (19.5\%) surveyed, subsisting on starvation diets $(<500 \mathrm{Kcals}$ per $\mathrm{CU} /$ day) and consumption of less familiar foods. Similar observations were made in the study conducted by Krishnamachari et al. (1974) in the drought-affected areas of Maharashtra. Drought surveys in the States of Andhra Pradesh, Karnataka, Orissa, Gujarat and Tamil Nadu by Pralhad Rao et al. (1989) revealed low yield of crops and lowered food consumption levels particularly of milk, pulses and sugar and jaggery, while none of the HHs were found consuming the starvation diets $(<500 \mathrm{kcals})$.

The State of Gujarat has been chronically experiencing drought during the past few years. Hence, a rapid cross sectional survey was carried out to assess the diet and nutritional status of the population and the food security status in the severely drought affected areas in the State during May and June 2000. Attempt was also made to study the coping strategies adopted by the HHs during food scarcity and to assess the extent of household participation in drought relief works, if any, in operation.

Gujarat ranks $13^{\text {th }}$ among the 17 major States of the country in terms of food grain production 
and tops in the production of cash crops such as, cotton, groundnuts and tobacco. The State is the largest producer of milk and contributes to $63 \%$ of the infant milk formulae produced in the country. Gujarat is also recognised as one of the leading industrialised States. It has the longest coastline, with average annual rainfall ranging from 380 to $2,100 \mathrm{~mm}$, in different parts of the state as reported by NFHS (1993).

\section{MATERIALS AND METHODS}

The Government of Gujarat declared 17 of the total 25 districts, as drought affected which received less than $50 \%$ of the normal rainfall, during the year. Out of these, 9 districts were declared as severely affected, wherein more than $75 \%$ of the villages had received less than $50 \%$ of the annual rainfall. From these nine districts, three districts viz., Dahod, Jamnagar and Kutch, were randomly selected for the survey. These three districts represented three different geographical regions of the State with more than $90 \%$ of the villages affected by drought. From each of the selected district, two severely affected blocks were randomly selected.

From each selected block, five villages were randomly selected from the list of the affected villages obtained from the revenue department. In each village, $40 \mathrm{HHs}$ were selected by probability proportion to population size (PPS) of various occupational groups such as landless labourers, marginal / small / large farmers, artisans and employees, using stratified random sampling procedure.

At the village level, secondary information such as the cropping pattern, extent of total area sown, rainfall, cattle wealth, irrigation and drinking water facilities for the current and previous years was collected from the village heads as well as from revenue department. Particulars of human or cattle deaths, if any, during the past three months were collected. Information on implemen-tation of relief works and other developmental programmes was also collected.

All the available individuals from the 40selected HHs were covered for measurement of heights and weights and clinical examination for presence of nutritional deficiency signs, by using standard equipment and procedures.

Household demographic and socio-economic particulars, food security status, coping strategies adopted during food scarcity, participation in drought relief works and developmental programmes, was collected in a sub-sample of $20 \mathrm{HHs}$, by using pre-tested proformae. According to International Conference on Nutrition (1992), HH food security was assessed based on the perception of the head of the $\mathrm{HH}$ about sufficiency/insufficiency of major food groups such as cereals, pulses, vegetables, milk and oils.

Household food intake was assessed by carrying out $24 \mathrm{hr}$ recall method of diet survey. (Thimmayamma et al., 1969), in a sub sample of 10 HHs (alternate HHs ) covered for household food security. The average daily intake of different foods and nutrients at the $\mathrm{HH}$ level were compu-ted per Consumption Unit (C.U). One consum-ption unit is coefficient of requirements of energy requirements of an adult male aged $20-39$ years, weighing $60 \mathrm{~kg}$ and doing sedentary work. In relation to this, the CUs were fixed for different age, sex groups, physiological status and activity. The average household intake of various nutrients (per CU/day) was computed, using food composition tables (Gopalan e al, 1990). The average consumption of various foods was compared with the recommended balanced diets for Indians (ICMR, 1981). The average intake of nutrients was compared with the 'Nutrient requirements and Recommended Dietary Allowances for Indians (ICMR, 1990). Protein calorie adequacy status of the HHs was assessed by the following procedure, adopted in the NNMB surveys (NNMB, 1999).

The protein and energy requirement curves are assumed to follow Gaussian distribution with a coefficient of variation of $15 \%$. The ICMR Expert Committee suggested that the average require-ments for energy as RDA, while for protein, "allowance" corresponding to Mean $+2 \mathrm{SD}$ of the actual requirements have been recommended. Thus, $2425 \mathrm{Kcal}$ of energy and $46 \mathrm{~g}$ of protein were taken to represent the average daily requirements, per CU. If in a given household, the daily per CU intake of protein and energy was found to be equal to or more than Mean -2 SE of the requirements, the household was considered as consuming adequate amounts of these nutrients.

Mean heights and weights were computed according to age and sex. The extent of undernutrition among 1-5 year children was assessed by using Gomez Classification (Gomez et al., 
1956) based on weight for age, and Standard Deviation (SD) Classification based on weight for age, height for age and weight for height (WHO, 1983, 1995) by using NCHS standards (Hamill et al., 1979). The nutritional status of adults was assessed based on Body Mass Index [Weight in $\mathrm{Kg} /(\text { Height in metres })^{2}$ ] as suggested by James et al. (1988).

The results were compared with that of survey carried out in Gujarat during earlier drought of 1987, and that reported for the State by NNMB during normal period.

\section{RESULTS}

A total of $600 \mathrm{HHs}$ were covered for demographic and socio-economic information, while food and nutrient intakes were assessed in 299 HHs from 30 villages, distributed over 6 blocks of the three districts. About 4727 individuals of different age and sex groups from $1200 \mathrm{HHs}$ were covered for nutritional assessment.

Community Profile: A majority of the HHs $(88 \%)$ were Hindu, while about $11 \%$ were Muslim. Thirty four percent of the HHs belonged to Scheduled tribes, followed by other communities (26\%), backward classes $(20 \%)$ and Scheduled castes $(20 \%)$.

Half the HHs (50\%) surveyed were landless, while the rest were marginal $(29.2 \%)$, small $(8.3 \%)$, and large $(12.5 \%)$ farmers. In about a fourth of the HHs $(23.5 \%)$, relatively more number of family members reportedly participated in labour work during drought than non-drought periods, to enhance their $\mathrm{HH}$ income.

General Conditions During Drought: Severe crop failure, increased unemployment, large scale migration of labour force, dried up water resources such as open wells, tube wells and tanks, emaciated cattle and cattle deaths were reported in the districts, the extent of which was relatively higher in the district of Dahod as compared to other two districts. Drinking water was supplied through tankers due to acute shortage in most of the villages. During the current drought, crop failure was reported by $39 \%$ of the HHs, while nearly $59 \%$ of the HHs reported the same during the current as well as previous two years. In about a half of the villages surveyed, the average rainfall during the year was reported to be less than $25 \%$ of the normal, while it was $25-50 \%$ in the rest of the villages. Considerable decline in the area under cultivation was reported between 1998 and 2000 . The extent of decline was about 33\% in khariff season while it was about $93 \%$ during rabi season. The extent of crop failure was about $40 \%$ for cereals, pulses, and millets, while it was about $75 \%$ for oil seeds. The heads of the villages reported a marginal increase in cattle deaths during current year, as compared to the previous years. A marked decline in water sources for irrigation was reported, as compared to previous year. About $87 \%$ of the tube wells, and $28 \%$ of the open wells in the villages surveyed, dried up during the year. Similarly, with regard to drinking water, $60 \%$ of the sources for piped water distribution system, $57 \%$ of the open wells, and $45 \%$ of the tanks dried up during the year. No loss of human life was reported in any of the villages surveyed. Migration of labourer families to the neighbouring towns was reported in 17 villages. However no deaths were reported due to starvation or diseases like gastroenteritis, which are the characteristic of drought.

Relief Measures: Drought relief measures like 'food for work' for generation of employment were reportedly undertaken for laying of roads, digging wells and deepening the tanks. Fodder was imported by rail from the States of Punjab, Haryana and Andhra Pradesh, by the Government and was supplied at subsidised rates, in most of the villages surveyed. Additional supplies of food grains were made available through Public Distribution System to combat the food scarcity, in 12 out of 30 villages surveyed. In about a third of the villages, food for work programme; drinking water supply through tankers, and Special Feeding programme for children and elderly population was under implementation.

Only $4 \%$ of the $\mathrm{HH}$ which possessed cattle such as cows, oxen, buffaloes and camels, reportedly had adequate fodder, while the rest, either depended on Government (57\%), borrowed the same from others $(37 \%)$ or received it from nongovernmental organisations (4\%). About $2 \%$ of the HHs had sent their cattle to the "cattle camps". Cattle deaths were reported by $26 \%$ of the HHs, during the previous three months, mostly due to scarcity of water and/or fodder. About a quarter of HHs (23\%) depended on supply of drinking water through tankers, mostly twice or thrice a week. 
Table 1: Participation of HHS (\%) in various drought relief programmes $(\mathbf{N}=\mathbf{6 0 0})$

\begin{tabular}{lc}
\hline Programme & Percent \\
\hline Food for work programme & 37.5 \\
Special nutrition programme for & 4.8 \\
$\quad$ pre school children & \\
Special nutrition programme for aged & 0.8 \\
Supply of drinking water & 26.7 \\
Supply of medicines & 18.7 \\
Employment Assurance Scheme & 1.5 \\
Supply of fodder to animals & 8.3 \\
Special ration through PDS & 2.0 \\
None & $\mathrm{Nil}$ \\
\hline
\end{tabular}

* Multiple responses.

The Government of Gujarat had initiated various relief measures to combat the drought situation (Table 1). About 38\% of the HHs reportedly participated in 'food for work' programme, followed by supply of drinking water $(26.7 \%)$, essential medicines (18.7\%) and cattle feed $(8.3 \%)$. Only about $2 \%$ of the HHs reportedly received additional ration of food grains through Public Distribution System.

Household Food Security: About 55-60\% of the heads of the HHs perceived food insufficiency with respect to cereals, pulses, fats and oils, milk and vegetables. When cereals and millets and pulses and legumes, which form the major portion of the Indian dietaries, were considered about $55 \%$ of the heads of the HHs assessed themselves as food insecure.

Coping Strategies: The coping strategies adopted by the HHs during food scarcity during current drought (Table 2) included consuming less costlier foods $(73 \%)$, borrowing cash or food grains from neighbours $(64 \%)$, reducing food consumption (47\%), managing with the available food stocks or money savings $(45 \%)$, seeking additional employment (10.5\%), migration to other areas in search of employment

Table 2: Distribution (\%) of households according to different coping strategies adopted during drought $(n=600)$

\begin{tabular}{lc}
\hline Coping strategies & Percent HHs \\
\hline Use food stocks / money savings & 45.2 \\
Purchase low cost foods & 73.3 \\
Borrow cash / food from neighbors & 63.7 \\
Gather food from forest areas & 2.3 \\
Seek additional employment & 10.5 \\
Seek government assistance & 8.3 \\
Reduce food consumption & 47.3 \\
Migration & 10.0 \\
Sell household or business assets. & 3.8 \\
\hline
\end{tabular}

* Multiple responses.
(10\%), seeking Governmental assistance $(8 \%)$ and selling off the household assets (4\%).

Food Intake: In general, the average daily consumption of cereals and millets $(500 \mathrm{~g} / \mathrm{CU})$ was well above the RDA of $460 \mathrm{~g}$. However, the mean intakes of income elastic foods like pulses $(27 \mathrm{~g})$, milk (102 g) and fats (15 g) were lower than the RDA. The intakes were relatively much lower in the district of Dahod. The intake of protective foods like green leafy vegetables and fruits was almost negligible. The average consumption of other vegetables ( $30 \mathrm{~g})$ and sugar and jaggery ( $25 \mathrm{~g}$ ) was lower than the RDA, while roots and tubers were consumed in quantities more than the recommended level.

It was observed that a variety of "cacti" were also consumed in few villages of Kutch and Dahod districts as a food supplement.

Nutrient Intakes: The diets were deficient in energy, vitamin A, riboflavin, niacin and vitamin $C$. The mean intake of protein was higher $(68 \mathrm{~g})$, while that of energy was lower (2271 kcal) than the RDA. The mean intake of calcium (427 mg), Iron $(28 \mathrm{mg})$, thiamin $(2 \mathrm{mg})$ and free folic acid $(76 \mathrm{mg})$ were satisfactory. The frequency distribution of HHs according to consumption of various nutrients, indicated that none of the HHs, fortunately was consuming $<500$ kcals of energy, a level suggestive of starvation diet. The proportion of $\mathrm{HHs}$ consuming $<70 \%$ of RDA of energy was about $23 \%$, which is interestingly, less than those reported during non-drought period by NNMB Gujarat state. With respect to micronutrients, barring thiamin and niacin, higher proportion of HHs were consuming less than $50 \%$ of RDA during current drought (Iron $25 \%$ vs $11 \%$, Vitamin 'A' 90\% vs 73\%, riboflavin 24\% vs $14 \%$ and folic acid $26 \%$ vs $4 \%$ ) as compared to that reported during non-drought period.

The distribution of HHs according to protein energy adequacy status indicated that about $55 \%$ of the HHs were consuming adequate amounts of both protein and energy, while $7 \%$ were consuming inadequate amounts of both the nutrients.

Nutritional Status: Severe form of PEM, such as kwashiorkor was conspicuously absent while about $0.2 \%$ of preschool children had marasmus. About $1.5 \%$ of pre-school children had conjunctival xerosis, a sign of vitamin A deficiency. Prevalence of Bitot spots was about $0.7 \%$, which was above the WHO criterion $(>0.5 \%)$, a level considered to be of public health 
Table 3: prevalence (\%) of undernutrition among pre school children during drought and non-drought periods

\begin{tabular}{lllccc}
\hline Indicator & Period & $N$ & $\begin{array}{c}\text { Below median } \\
-3 S D\end{array}$ & $\begin{array}{c}\text { Median }-3 S D \\
\text { to Median }-2 S D\end{array}$ & $\chi^{2}$ Value \\
\hline \multirow{3}{*}{ Weight for age } & Drought & 718 & 27.3 & 38.4 & $\chi^{2}=8.87(\mathrm{p}<0.01)$ \\
& Non-drought & 647 & 38.1 & 36.5 & $\chi^{2}=31.94(\mathrm{p}<0.01)$ \\
Height for age & Drought & 718 & 21.9 & 26.9 & $\chi^{2}=0.20(\mathrm{p}>0.05)$ \\
Weight for height & Non-drought & 641 & 44.8 & 24.3 & 22.1 \\
& Drought & 718 & 7.4 & 21.8 & \\
& Non-drought & 641 & 8.1 & & \\
\hline
\end{tabular}

* NCHS standards used

Non - drought - NNMB: National Nutrition Monitoring Bureau (Gujarat state - 1996)

significance.

Distribution of pre-school children according to Gomez classification indicated that, the overall prevalence of moderate and severe undernutrition was about $43 \%$ and $8 \%$ respectively. About $40 \%$ of the children had mild undernutrition. The prevalence of severe undernutrition was marginally higher $(9.5 \%)$ among younger age group (1-3 years) as compared to their older counter parts (3-5 years) $(7.2 \%)$. A higher proportion of boys $(54.2 \%)$ exhibited moderate to severe undernutrition as compared to girls $(47.8 \%)$.

Table 3 shows the distribution of children according to underweight, stunting and wasting by Standard Deviation classification using NCHS standards. The proportion of children with underweight ( $<$ Median $-2 \mathrm{SD}$ ) was about $66 \%$, of which $27 \%$ had severe degree of underweight ( $<$ Median -3SD). About 49\% of the children had various degrees of stunting $(<$ Median-2SD), of which The extent of severe stunting ( $<$ Median $-3 \mathrm{SD}$ ) was about $22 \%$. The magnitude of wasting $(<$ Median-2SD of weight for height) was about $30 \%$, which is similar to that reported by NNMB, while $7 \%$ of the children had severe wasting (weight for height $<$ Median-3SD). Surprisingly the prevalence of underweight and stunting was significantly less $(\mathrm{p}<0.01)$ during drought as compared to non-drought situations. However no significant difference $(\mathrm{p}>0.05)$ was observed in the prevalence wasting among pre school children during drought and non-drought periods.

Distribution of adults according to BMI status indicated that the prevalence of chronic energy deficiency $(\mathrm{BMI}<18.5)$ was relatively more among males $(49 \%)$ as compared to females $(36 \%)$ (Table 4$)$. No significant differences in
Table 4: Distribution (\%) of adults according to bmi status during drought and non-drought periods

\begin{tabular}{|c|c|c|c|c|c|}
\hline \multirow{2}{*}{$\begin{array}{l}\text { Nutritional } \\
\text { Grade }\end{array}$} & \multirow[t]{2}{*}{$B M I$} & \multicolumn{2}{|c|}{ Males } & \multicolumn{2}{|c|}{ Females } \\
\hline & & $\begin{array}{l}\text { Drought } \\
\text { (763) }\end{array}$ & $\begin{array}{c}\text { Non- } \\
\text { drought } \\
\text { (1044) }\end{array}$ & $\begin{array}{c}\text { Drought } \\
\text { (417) }\end{array}$ & $\begin{array}{c}\text { Non- } \\
\text { drought } \\
\text { (1691) }\end{array}$ \\
\hline CED-III & $<16.0$ & 11.7 & 16.7 & 8.5 & 15.4 \\
\hline CED-II & $16.0-17.0$ & 13.9 & 17.3 & 9.2 & 14.1 \\
\hline CED-I 1 & $17.0-18.5$ & 23.1 & 28.9 & 18.1 & 26.4 \\
\hline \multirow[t]{2}{*}{ Total CED } & $<18.5$ & 48.7 & 62.9 & & 55.9 \\
\hline & & \multicolumn{2}{|c|}{$\begin{array}{l}\chi^{2}=0.78: \\
(p>0.05)\end{array}$} & \multicolumn{2}{|c|}{$\begin{array}{l}\chi^{2}=1.04 \\
(p>0.05)\end{array}$} \\
\hline
\end{tabular}

CED: Chronic energy deficiency

Non-drought -NNMB: National Nutrition Monitoring Bureau (Gujarat state - 1996)

the prevalence of chronic energy deficiency were observed during drought and non-drought periods.

\section{DISCUSSION}

Assessment of the extent and magnitude of the impact of drought on the nutritional profile of the general population has been carried out in the past by several workers (Swaminahan et al., 1967; Krishnamachari et al., 1974; Pralhad Rao et al., 1989) in different States of India. Though a reduction of food intake was recorded in most of the studies, no significant changes in body weights were observed. Similar observations were made in the study conducted in Gujarat during 1987.

The present survey revealed, that there was failure of monsoon, leading to significant drop in agricultural production, affecting the landless labour, small and marginal farmers, who constituted a major section of the rural population. The drought had disrupted the rural economy resulting in increase in the proportion 


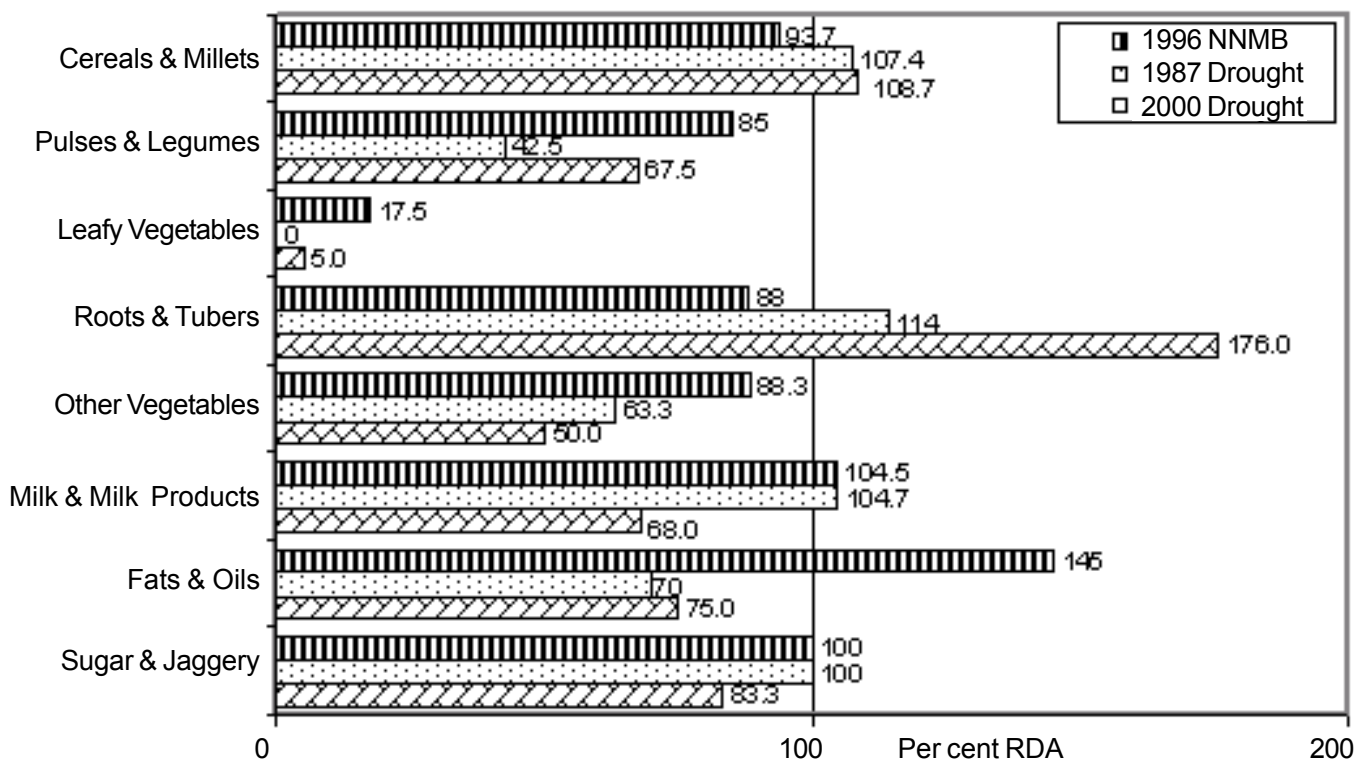

Fig. 1 Mean intake of food products as per cent of RDA.

of labour-ers, among the marginal and small farmers and their migration to the cities, in search of employment; however the relatively higher proportion of HHs reporting the crop failure during of the previous two years as compared to the current drought indicates less severity of the situation.

The community resorted to several coping strategies, like consuming less costlier foods, consuming the food stocks, spending from money savings, borrowing of cash or kind, and reducing food intake. These strategies may not be sustained in the event of recurrence of drought.

Diet surveys, revealed that the mean consumption of cereals \& millets and roots \& tubers was more than RDA as was reported during 1987 drought $\&$ were higher than that reported during non-drought periods (Fig. 1). Absence of HHs being on subsistence diets as well as starvation deaths could partly be reflecting better management of drought relief measures such as, effective supply of food grains through public distribution system at subsidised rates, and the improved purchasing power of the households by the wages gained through drought relief programmes. Inadequate intake of protective, and income elastic foods was reflected in the lower intake of nutrients such as iron, riboflavin and vitamin $\mathrm{A}$. The protein-calorie adequacy status of HHs was better during the present survey as compared to that reported during nondrought period. The overall impact of the current drought in terms of food and nutrient availability was comparable to that of 1987 drought survey. In general, the current drought did not affect the food and nutrient intake of the population, perhaps due to better management of the situation.

No significant changes in the nutritional status of the pre-school children, adolescents and the adults was observed during the current drought as compared to non drought period reported for the State by NNMB (Fig.2). The nutritional status of pre-school children during the present survey as assessed by Gomez classification, was found to be better than that reported by 1987 drought survey. The proportion of children with underweight, stunting and wasting was either less or comparable to that of NNMB surveys. The prevalence of CED among both the males and females in the present study was observed to be less than that reported for the State by NNMB surveys during non-drought periods. The results indicated that the proportion of pre-school children, school age children and adolescents with various grades of undernutrition was similar among both the groups of land less 


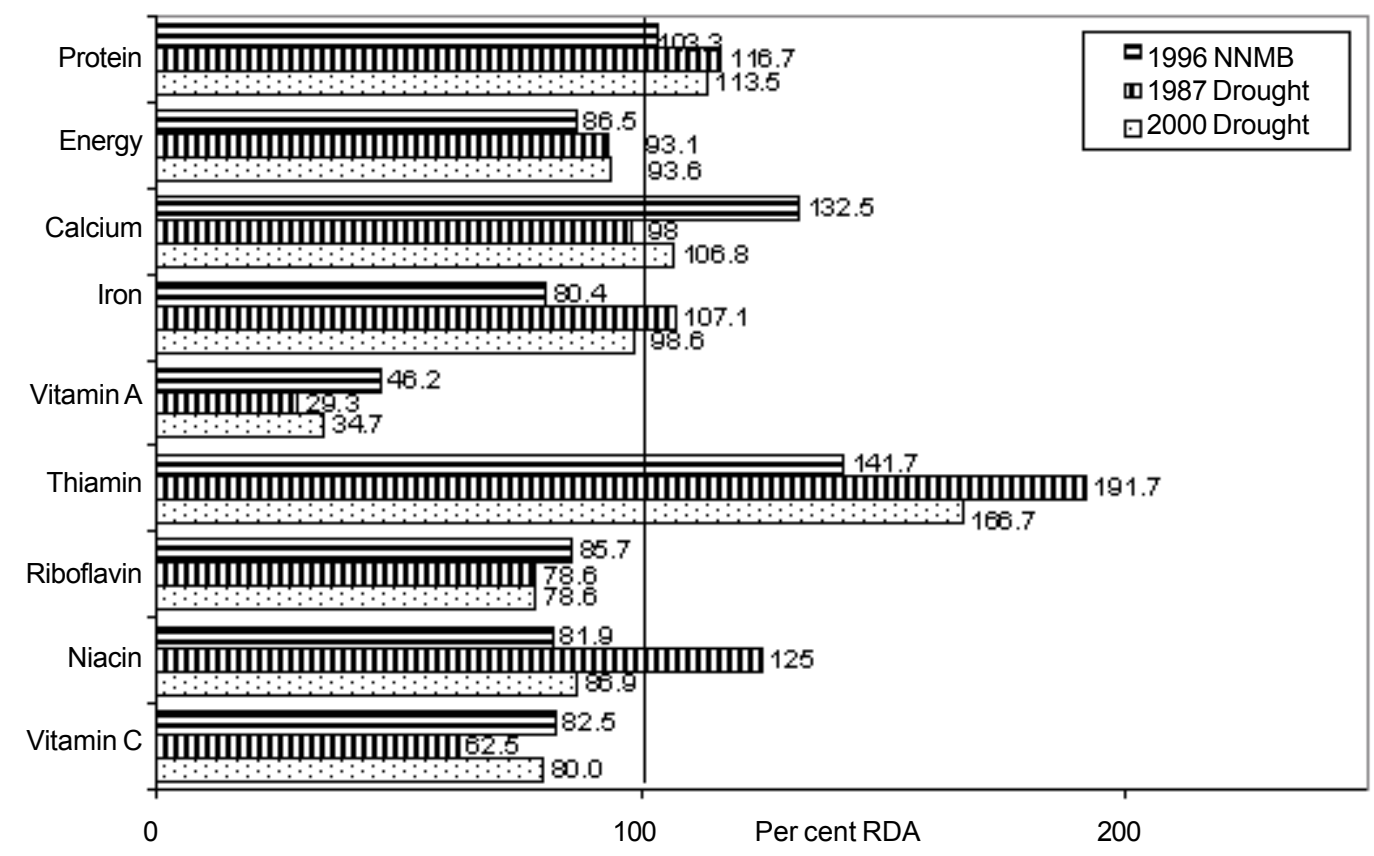

Fig. 2. Mean intake of nutrients (CU/day) as per cent of RDA

labour and those HHs holding varying extent of land. $(\mathrm{p}>0.05)$.

Thus present study though indicated failure of crops, increased number of cattle deaths, drying up of water sources both for irrigation and drinking purposes, increased household food insecurity, lowered food and nutrient intakes, did not have significant adverse effect on the nutritional status of the population. This may be due to better management of various drought relief programmes in the State of Gujarat. However, owing to chronicity of drought, it is necessary to undertake preventive measures such as supplementary feeding programme, strengthening of PDS, creation of subsidiary employment, maintaining adequate food stocks and fodder, forecasting the drought and timely warning of the population accordingly, on a permanent basis.

\section{ACKNOWLEDGEMENTS}

We express our gratitude to Dr. N.K. Ganguly, Director General, Indian Council of Medical Research, for providing financial assistance, and the former Director, Dr. (Mrs.) Kamala Krishnaswamy, National Institute of Nutrition,
Hyderabad, for permitting to carryout the survey. Our thanks are due to Mr. U. D. Awasthi, Mr. K. Nageswara Rao, Mr. B. Pothuraju, Mr. Ch. Krishna, and Mr. N.Srinivasachari, Technical Assistants, Mr. C. Saibabu,. Mr. G. Govindarajulu, Mr. S. P. V. Prasad, Mr. K. Sreerama Krishna, Ms. G. Madhavi, Lab Assistants and Mr. J.Venkata Swamy, Ms. Madhu Bindu, Ms. Jyotsna and Mr. Sampath Kumar Reddy, Field Assistants for their technical assistance. We are also thankful to Ms. G. Prashanthi, Stenographer and Mr. G. Hanumantha Rao, Personal Assistant for their secretarial assistance. We are extremely grateful to the community for their unstinted cooperation, without which the survey would not have been possible.

\section{REFERENCES}

Gomez, F., Galvan, R., Frank, S., Cravioto, J., Chavez, R. and Vasquiz J.: Mortality in second and third degree malnutrition. J. Trop. Paed., 2: 77-83 (1956).

Gopalan, C., Ramasastry, B. V., Balasubramanian, S. C., Narasinga Rao, B. S., Deosthale, Y. G. and Pant, K. C.: Nutritive Value of Indian Foods. National Institute of Nutrition, I.C.M.R., Hyderabad, India (1990).

Hamill, P. V. V., Drizid, T. A., Johnson, C. L., Reed, R. B. Roche AF. and Moore, W. M.: Physical Growth: National Centre 
International Conference on Nutrition-Major Issues for Nutrition Strategies for Improving Household Food Security. Theme paper No.i, FAO, WHO, (1992).for Health statistics percentiles. Amer. J. Clin. Nutr., 32: 607 629 (1979)

ICMR.: Recommended Dietary Intakes for Indians. Indian Council of Medical Research, New Delhi (1981).

ICMR.: Nutrient Requirements and Recommended Dietary Allowances for Indians. Indian Council of Medical Research. A Report of the Expert Group of the ICMR, New Delhi (1990).

James, W. P. T., Anna Perro Lyzzi and Waterlow, J. C.: Definition of chronic energy deficiency in adults. European J. Clin. Nutr., 42: 969-981 (1988).

Krishnamachari, K.A.V.R, Pralhad Rao, N and Visweswar Rao, K.: Food and nutritional siituation in the drought affected areas of Maharashtra - A survey and recommendations. Indian J. Nutr. Dietet., 11: 20 (1974).

National Family Health Survey, Gujarat. Population Research Centre, Faculty of Science, M.S. University of Baroda,
Vadodara, International Institute for Population Sciences, Bombay (1993)

National Nutrition Monitoring Bureau: Report of the Second Repeat Survey-Rural. Tech. Rep. Series No. 18, National Institute of Nutrition, ICMR, Hyderabad (1999).

Pralhad Rao, N.: Diet and Nutrition during drought - An Indian Experience. Disasters, 13: 61-72 (1989).

Swaminathan, M.C., Visweswar Rao, K. and Hanumantha Rao, D.: Food and Nutrition situation in drought affected areas of Andhra pradesh. Indian J Med Res., 55: 209-17 (1967).

Thimmayamma, B. V. S. and Hanumantha Rao, D.: A comparative study of the oral questionnaire method with actual observation of the dietary intake of the pre-school children. J. Nutr. Dietet., 6: 177-181 (1969).

WHO.: Physical Status: The use and Interpretation of Anthropometry. Report of WHO Expert Committee., WHO Tech. Rep. Series, 854, WHO, Geneva (1995).

WHO.: Measuring Changes in Nutritional Status. WHO, Geneva (1983). 